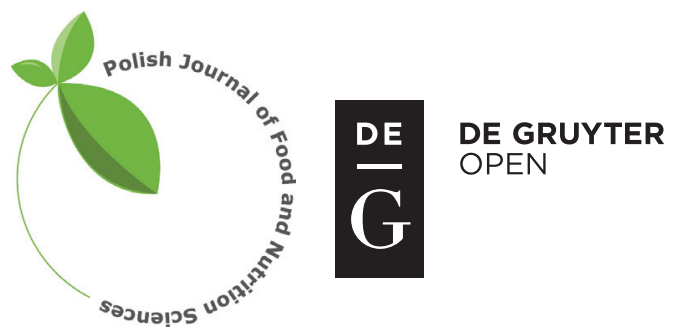

Pol. J. Food Nutr. Sci., 2016, Vol. 66, No. 2, pp. 67-75 DOI: $10.1515 /$ pjfns-2015-0040 http://journal.pan.olsztyn.pl

Review article

Section: Nutritional Research

\title{
Goji Berry (Lycium barbarum): Composition and Health Effects - a Review
}

\author{
Bartosz Kulczyński*, Anna Gramza-Michatowska \\ Faculty of Food Science and Nutrition, Poznań University of Life Sciences, Wojska Polskiego 31, 60-624 Poznań, Poland
}

Key words: goji berries, Lycium barbarum, bioactive compounds, antioxidants, polyphenols, health benefits

Goji berries contain many nutrients and bioactive compounds which allowed to classify them as superfruits. A short description of the fruits is presented together with cultivation requirements. The chemical composition of the berries and their health-promoting properties are described later in this literature review. Based on the available data, their potentially beneficial application in dietary prevention of diseases of affluence, such as diabetes, cardiovascular diseases and cancer, is elaborated. We also refer to the safety of Goji consumption in the context of ingredients potentially harmful for human health, allergic reactions and the interactions with other substances.

\section{INTRODUCTION}

The rapid increase in diseases of prosperity has led to more intensified research into substances contributing to their prevention and treatment. Results of many investigations showed that life style changes, such as a well-balanced diet and physical exercise, may effectively prevent the occurrence of many diseases [Amagase \& Farnsworth, 2011; Amani \& Gill, 2013; Batcagan-Abueg et al., 2013; Gramza-Michałowska et al., 2011; Gramza-Michałowska, 2014; Marrazzo et al., 2014; Shashirakha et al., 2015]. Based on the current analysis of food, as well as clinical and epidemiological research, scientists are searching for products characterized by better health-promoting properties. Raw materials that can be used for the production of properly engineered food are also being investigated [Ahmad et al., 2015; Hęś et al., 2011; Kmiecik et al., 2015]. Bioactive food is an emerging field in the context of health and nutrition. Many people and associations have defined its importance. However, the American Dietetic Association (ADA) has proposed the most accurate definition of the bioactive ingredients of food: "Bioactive food components are physiologically active constituents in foods or dietary supplements derived from both animal and plant sources, including those needed to meet basic human nutrition needs, that have been demonstrated to have a role in health and to be safe for human consumption" [Saldanha, 2004]. Carotenoids, flavonoids, isoflavones, phytoestrogens, sterols, stanols, vitamins and chemical elements, fiber, fatty acids, probiotics and prebiotics as well as bioactive peptides are constituents of bioac-

\footnotetext{
* Corresponding Author: Tel.: +4861 8487331, Fax: +4861 8487430

E-mail: bartosz.kulczynski@up.poznan.pl (B. Kulczyński)
}

tive food [Guine et al., 2010; Milner, 2004; Hęś et al., 2011; Reguła \& Gramza-Michałowska, 2013; Sharma \& Singh, 2010]. Research showed that bioactive compounds of food origin may fulfill many health-promoting functions in the human organism [Astrup et al., 2010; Castro et al., 2005; Cho et al., 2013; Kris-Etherton et al., 2002; Liu, 2013; Meydani \& Hasan, 2010; Moller et al., 2008; Morimoto et al., 2012; Reguła \& Gramza-Michałowska, 2010; Srinath \& Katan, 2004]. They may lower cholesterol levels and blood pressure, enhance the immune system, regulate blood glucose levels and hormonal balance, help in the reduction of weight, slow down the ageing processes and counteract cancer.

\section{ORIGIN AND DESCRIPTION OF GOJI FRUITS}

Goji produces an ellipsoid orange-red berry approximately $2 \mathrm{~cm}$ deep with a sweet-and-tangy flavor. The Goji berry is the fruit of $L$. barbarum and $L$. chinense in the family Solanaceae that ranges from tomato and potato to eggplant. The author of the species name, L. barbarum, was Carl Linnaeus in 1753 , whereas $L$. chinese was named 15 years later by Philip Miller. It is also known as Chinese wolfberry, possibly because Chinese farmers observed wolves eating these berries. L. barbarum and $L$. chinense are native to Asia, primarily in the central north region called Ningxia Hui Autonomous Region. In addition, commercial volumes of wolfberries grow in the Chinese regions of Xinjiang, Shaanxi, Gansu, Hebei, Inner Mongolia, and also in Japan, Korea, and Taiwan. China, the main supplier of wolfberry, yields 95,000 tones of Goji fruits, derived from 82,000 hectares. Goji berries have been an important part of traditional Chinese medicine for more than 2000 years due to their rich chemical composition and medical properties. As a food, dried wolfberries are traditionally cooked before consumption, used as herbal tea, 
TABLE 1. Composition of bioactive carotenoid fractions in goji berries (Lycium barbarum).

\begin{tabular}{|c|c|c|}
\hline \multirow{2}{*}{ Compound } & \multicolumn{2}{|c|}{ References } \\
\hline & Wang et al. [2010] & Inbaraj et al. [2008] \\
\hline $\begin{array}{l}\text { Carotenoid } \\
\text { fractions }\end{array}$ & $\begin{array}{l}\text { 13- or } 13 \text { '-cis- } \beta \text {-carotene } \\
\text { (8.97 mg/g), all-trans- } \\
\text { - } \beta \text {-carotene (16.6 mg/g), } \\
\text { 9- or 9'-cis- } \beta \text {-carotene } \\
(10.3 \mathrm{mg} / \mathrm{g}) \text {, neoxanthin } \\
(13.2 \mathrm{mg} / \mathrm{g}) \text {, all-trans- } \beta \text { - } \\
\text { cryptoxanthin }(53.3 \mathrm{mg} / \mathrm{g}) \text {, } \\
\text { 9- or 9'-cis- } \beta \text { - } \\
\text {-cryptoxanthin }(5.61 \mathrm{mg} / \mathrm{g}) \text {, } \\
\text { 9- or 9'-cis-zeaxanthin } \\
\text { (39.3 } \mathrm{mg} / \mathrm{g}), 13 \text { - or } 13 \text { '-cis- } \\
\text { zeaxanthin }(4.85 \mathrm{mg} / \mathrm{g}), \\
\text { 15- or } 15 \text { '-cis-zeaxanthin } \\
\text { (32.8 mg/g), all-trans- } \\
\text { zeaxanthin (1326 mg/g) }\end{array}$ & $\begin{array}{l}\text { all-trans-zeaxanthin } \\
(1.4 \mu \mathrm{g} / \mathrm{g}), \text { all-trans- } \beta \text { - } \\
\text {-carotene }(23.7 \mu \mathrm{g} / \mathrm{g}) \text {, } \\
\text { zeaxanthin monopalmitate } \\
(11,3-62.8 \mu \mathrm{g} / \mathrm{g}), \\
\beta \text {-cryptoxanthin } \\
\text { monopalmitate } \\
(32.9-68.5 \mu \mathrm{g} / \mathrm{g}), \\
\text { zeaxanthin dipalmitate } \\
(1143.7 \mu \mathrm{g} / \mathrm{g})\end{array}$ \\
\hline
\end{tabular}

as well as in Chinese soups, or in combination with meat and vegetarian meals. Goji fruits are also used for the production of juice, wine and tincture [Gross, 2006; Amagase \& Farnsworth, 2011; Benzie \& Wachtel-Galor, 2011; Potterat, 2010]. Goji is a plant introduced to Europe in the 18th century [Sopher, 2013]. L. barbarum prefers well-drained slightly alkaline soils [Peaceful Valley Farm Supply, 2013], and sunny locations. Germination temperature is $21-23^{\circ} \mathrm{C}$, whereas for L. barbarum this is $15-25^{\circ} \mathrm{C}$ and is resistant to low temperatures, first fruition however is typically observed in 3-year-old plants [Dominion Seed House, 2013; Marczyński \& Piotrowski, 2013].

\section{CHEMICAL COMPOSITION OF GOJI BERRY}

Goji berries are not without reason termed a "superfruit". Wolfberries contain many nutrients with high biological activity, such as polysaccharide complexes, carotenoids, phenylpropanoids and others, as characterized below. The polysaccharide complex is the most important and the most abundant group of compounds present in Goji fruits. They are present in the water-soluble form of highly branched L. barbarum Polysaccharides (LBP) with a molecular weight of 8-214 kDa, and comprise $5-8 \%$ of the total dry matter of the fruits. Their composition includes six types of monosaccharides: arabinose, rhamnose, xylose, mannose, galactose, glucose, galacturonic acid and eighteen amino acids [Amagase \& Farnsworth, 2011]. Research of dos Reis et al. [2014] showed that goji berries fermentation yielded $87 \%$ sugars decrease within $24 \mathrm{~h}$, without losses in polyphenol content, however carotenoid content was reduced by $17 \%$. Carotenoids present in Goji are the second highly significant group of biologically-active constituents with health promoting properties. They are responsible for the characteristic orange-red color of the berries. They comprise $0.03-0.5 \%$ of the dry matter of the fruits (Table 1). Zeaxanthin is one of the most common carotenoids present in Goji (31-56\% of the total carotenoid pool). It is present in the form of dipalmitin zeaxanthin. Goji is considered the best natural source of dipalmitin zeaxanthin known so far. Beta-carotene, neoxanthin, cryptoxanthin are also present at lower concentrations [Peng et al., 2005; Wang et al., 2010]. Phenylpropanoids are bioactive compounds with a very high antioxidant capacity. Analysis of the antioxidant activity and phenylpropanoids in different medicinal Chinese herbs has confirmed the presence of these constituents in Goji berry at the level of $22.7 \mathrm{mg}$ (gallic acid equivalent/g extract) [Guo et al., 2008]. A comparison of the phenolic profile and vitamin $\mathrm{C}$ content of Goji berry fruit is presented in Table 2. Wang et al. [2010] isolated and measured the levels of individual flavonoid fractions. The most common were quercetin-3-O-rutinoside, kaempferol-3-O-rutinoside, chlorogenic acid, caffeic acids and small amounts of caffeoylquinic acid and p-coumaric acid [Zhong et al. 2013]. Goji berries contain $1.0-2.7 \%$ of free amino acids, with the most abundant being proline. The presence of taurine and betaine has also been confirmed [Potterat, 2010]. Additional compounds present in Goji fruits are: vitamins, such as thiamin, riboflavin, and ascorbic acid with its glucosidic precursor (2-O- $\beta$-D-glucopyranosyl). The concentration of vitamin $\mathrm{C}$ was found at $42 \mathrm{mg} / 100 \mathrm{~g}$ [Donno et al., 2015]. Llorent-Martínez et al. [2013] confirmed the presence of many mineral elements, the most common of which were potassium $(1460 \mathrm{mg} / 100 \mathrm{~g})$, sodium (550 mg/100 g), phosphorus (184 mg/100 g), magnesium $(90 \mathrm{~g} / 100 \mathrm{~g})$ and calcium $(50 \mathrm{mg} / 100 \mathrm{~g})$. Interestingly, the iron concentration of $5.5 \mathrm{mg} / 100 \mathrm{~g}$ is high in respect to Dietary Reference Intake (DRI). Goji also contains organic acids, such as citric acid, malic acid, fumaric acid and shikimic acid [Mikulic-Petkovsek et al., 2012]. The most common fatty acids are: palmitic acid, linoleic acid and myristic acid. According to literature, Goji berries provide $370 \mathrm{kcal} / 100 \mathrm{~g}$ dried fruits [Gross, 2006].

\section{HEALTH-PROMOTING PROPERTIES OF GOJI BERRIES}

\section{Hypoglycemic properties}

Many experiments have been performed in order to understand how Goji acts on the way the body handles carbohydrates. Luo et al. [2004] have investigated the correlation between supplementation with different polysaccharide fractions of Goji fruit and the levels of glucose in blood. The effects of L. barbarum preparations in alloxan-induced diabetic rabbits have been investigated by measuring a blood glucose level. Decreased blood glucose levels ( $\geq 3.9 \mathrm{mmol} / \mathrm{L}$ ) were recognized as substantial hypoglycemic effects. Results of the experiment were unambiguous. It was found that all Goji preparations resulted in significantly decreased blood glucose levels after 10 days of treatment in the tested animals, indicating that there was a substantial hypoglycemic effect. Moreover, the hypoglycemic effect of purified polysaccharide fractions was more significant than those of water decoction and crude polysaccharide fractions, implying that L. barbarum polysaccharides were major bioactive components in the hypoglycemic effect. Guowen et al. [2010] performed a similar experiment and the results were propitious. Mice treated with L. barbarum extracts were characterized by significantly reduced blood glucose levels compared to the diabetic control group. Many experiments confirm diabetes is correlated with high oxidative stress. Hyperglycemia-induced oxidative stress 
TABLE 2. Phenolic profile and vitamin C content of Goji berry (Lycium barbarum) fruit.

\begin{tabular}{|c|c|c|c|c|}
\hline Chemical compound & & $\begin{array}{c}(\mathrm{mg} / 100 \mathrm{~g} \mathrm{fw}) \\
\text { Donno et al. }[2015]\end{array}$ & $\begin{array}{c}\text { (mg/g ext) } \\
\text { Wang et al. [2010] }\end{array}$ & $\begin{array}{c}(\mu \mathrm{g} / \mathrm{g} \mathrm{pm}) \\
\text { Mocan et al. }[2014] \\
\end{array}$ \\
\hline \multirow{4}{*}{ Cinnamic acids } & Caffeic acid & 110.84 & 3.73 & $<0.02$ \\
\hline & Chlorogenic acid & 113.18 & 12.40 & 5899.29 \\
\hline & Coumaric acid & 111.32 & 6.06 & 30.29 \\
\hline & Ferulic acid & 125.80 & n.e. & $<0.02$ \\
\hline \multirow[t]{7}{*}{ Flavonols } & Hyperoside & 116.27 & n.e. & n.e. \\
\hline & Isoquercitrin & n.d. & n.e. & $<0.02$ \\
\hline & Quercetin & n.d. & n.e. & 5.59 \\
\hline & Quercetin-diglycoside & - & 66.00 & n.e. \\
\hline & Quercitrin & n.d. & n.e. & 13.00 \\
\hline & Rutin & n.d. & 42.00 & 5646.66 \\
\hline & Kaempferol-3-O-rutinoside & - & 11.30 & n.d. \\
\hline \multirow[t]{2}{*}{ Benzoic acids } & Ellagic acid & n.d. & n.e. & n.e. \\
\hline & Gallic acid & 15.31 & n.e. & n.e. \\
\hline \multirow[t]{2}{*}{ Catechins } & Catechin & 118.76 & n.e. & n.e. \\
\hline & Epicatechin & 229.18 & n.e. & n.e. \\
\hline \multirow[t]{2}{*}{ Ellagitannins } & Castalagin & n.d. & n.e. & n.e. \\
\hline & Vescalagin & n.d. & n.e. & n.e. \\
\hline Vitamin & Vitamin C & 48.94 & & \\
\hline
\end{tabular}

fw - fresh weight; ext - extract; pm - plant material; n.d. - not detected; n.e. - not evaluated

may be implied in diabetes onset. The effect of $L$. barbarum treatment on antioxidative protective mechanisms has been investigated in streptomycin-induced diabetic rat kidneys. The antioxidative activity of superoxide dismutase, catalase and glutathione was significantly increased after Goji polysaccharide fractions treatment. Moreover, free radical scavenging activity was also elevated [Li, 2007]. Another experiment confirmed the increased activity of antioxidant enzymes in kidneys, lungs and liver of polysaccharide fractions-fed mice. Moreover, the same experiment revealed that animals on high-fat diets supplemented with polysaccharide fractions had statistically lower levels of glucose, compared to mice on high-fat diets only [Ming et al., 2009].

\section{LIPID-LOWERING PROPERTIES IN BLOOD}

The effect of polysaccharide fractions supplemented highfat diet has been analyzed in mice in order to evaluate its impact on total cholesterol, its LDL and HDL fractions and triglyceride levels. Mice administered polysaccharide fractions supplemented high-fat diets were characterized by decreased concentrations of total cholesterol, LDL-cholesterol and triglycerides and increased HDL-cholesterol concentrations compared to mice on high-fat diets without polysaccharide fractions [Li, 2007]. Cui et al. [2011] obtained identical results. Pai et al. [2013] performed similar experiments with rats on high-fat diets. Two groups of animals were tested, a control group (normal diet) and a group on high-fat diets supplemented with hypoglycemic drug-statin (Atorvastatin). The results are consistent with previous findings. Polysaccharide fractions supplementation caused a decrease in total cholesterol, LDL-cholesterol fraction and triglyceride concentration compared to the rats on the control high-fat diet. Moreover, the polysaccharide fractions-supplemented rats were characterized by statistically lower triglyceride and statistically higher HDL-cholesterol concentrations compared to the atorvastatin-treated rats [Pai et al., 2013]. Guowen et al. [2010] performed an alternative analysis where the effect of the polysaccharide fractions supplementation on the diabetic mice lipid profile was evaluated. The group of animals supplemented with Goji extract had significantly lower concentrations of triglycerides and total cholesterol compared to the diabetic control group. Zhao et al. [2005] obtained similar results confirming the hypothesis that Goji polysaccharide fractions supplementation has a positive effect on the lipid profile of rats through decreasing total cholesterol and triglyceride concentrations. Luo et al. [2004] performed an experiment with alloxan-induced diabetic rabbits and found that polysaccharide fractions supplementation resulted in a hypolipemic effect and a simultaneous increase in HDL-cholesterol concentrations. Then, Cheng et al. [2011] investigated changes in the lipid profile of polysaccharide fractionssupplemented rats with alcohol defects of the liver and found much lower levels of triglycerides, total cholesterol and LDL-cholesterol fraction, and a simultaneously increased HDL-cholesterol concentration. 


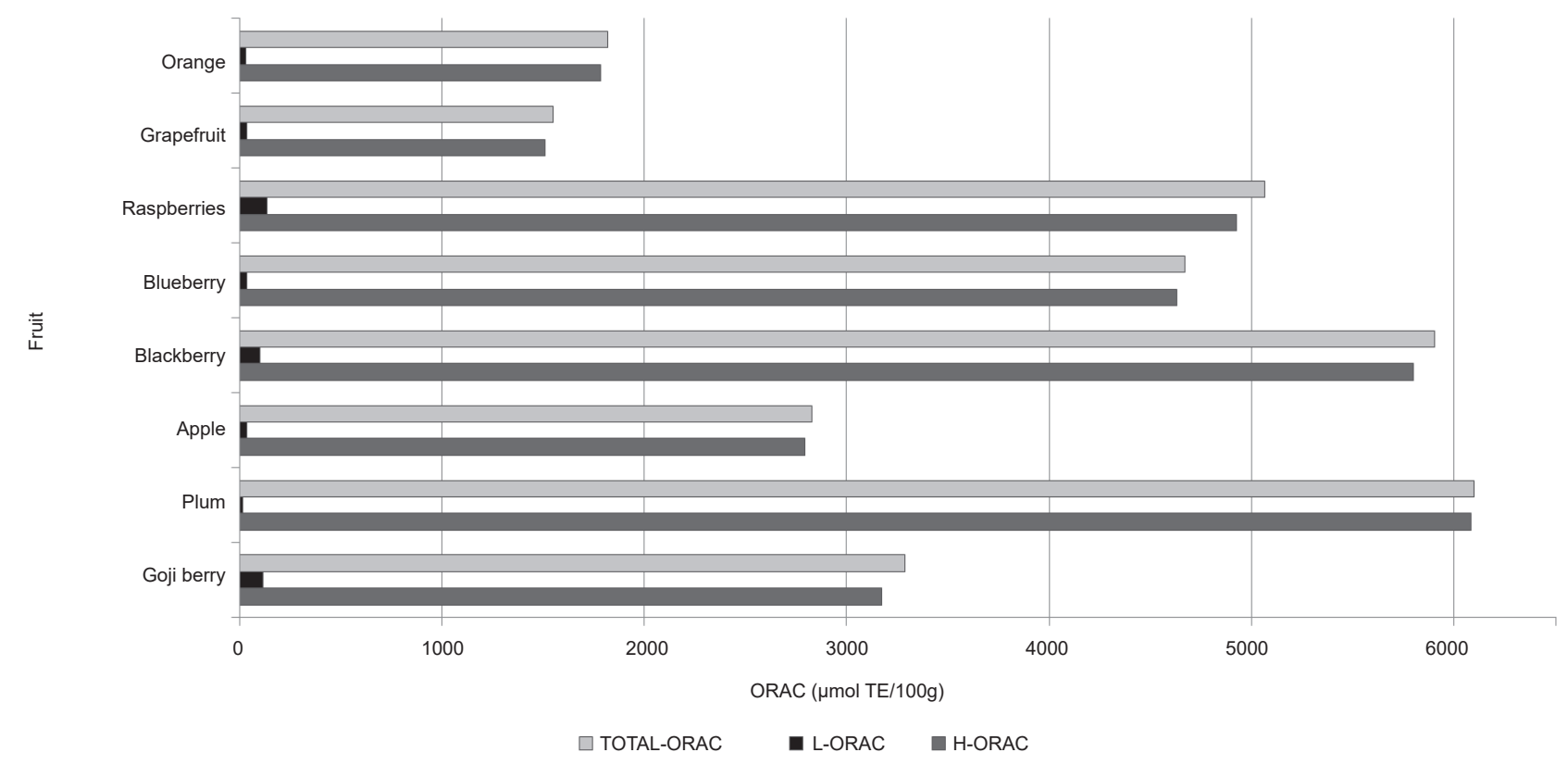

FIGURE 1. ORAC values for antioxidant activity of different fruits

ORAC - Oxygen Radical Absorbance Capacity; H-ORAC - hydrophilic for water soluble antioxidants ORAC value; L-ORAC - lipophilic for lipid soluble antioxidants ORAC value; TE - Trolox equivalents; compilation of results [USDA, 2010].

IMMUNOSTIMULATORY AND ANTICANCER
ACTIVITY

Traditional Chinese medicine has utilized compounds present in Goji fruits to prevent the onset and progression of cancer. Goji also exhibits immunostimulatory activity. It has been confirmed in many tests that compounds present in Goji berries have pro-apoptotic and antiproliferative activity against cancer cells [Tang et al., 2012]. Gan et al. [2004] confirmed that Goji polysaccharide fractions could significantly inhibit the growth of transplantable sarcoma in mice, moreover increased macrophage phagocytosis and antibody secretion by spleen cells. Furthermore, spleen lymphocyte proliferation was enhanced in comparison with the afflicted control group. It was also found that Goji polysaccharide fractions could significantly reduce lipid peroxidation in mice and inhibit proliferation of liver cancer cells [Zhang et al., 2005]. Mao et al. [2011] also showed the anticancer properties of polysaccharide fractions. They proved the anticancer effect of $L$. barbarum polysaccharides on colon cancer cells through G0/G1 phase arrest. Zhu \& Zhang [2013] also confirmed the antiproliferative activity of Goji polysaccharide fractions against HeLa cells, probably through induction of apoptosis. Zhang et al. [2011 a,b] also observed a similar effect. They found that the anticancer effect of Goji berry was attributed to 2-O-(beta-D-glucopyranosyl) ascorbic acid. Goji fruits are also a source of scopoletin. It has been proven that scopoletin induces inhibition of human prostate cancer cell proliferation (PC-3) [Liu et al., 2000]. Amagase with cooworkers [2009b] investigated the effect of Goji juice on healthy Chinese adults. Lymphocyte, interleukin- 2 (IL-2) and immunoglobulin $\mathrm{G}$ levels in the treated group were significantly higher than those in the placebo group. Gan et al. [2003] observed activation of the immune system components through the administration of a $L$. barbarum polysaccharide-protein complex that increased the expression of interleukin- 2 and tumor necrosis factor-alpha at both mRNA and protein levels in human peripheral blood mononuclear cells. Glycans and glycoconjugates present in Goji exert a stimulatory effect on the expression of NF- $\mathrm{kB}$ (nuclear factor kappa-light-chainenhancer of activated B cells) and the activator protein 1(AP-1) [Peng et al., 2001]. Chen et al. [2008] confirmed activation NF-kB and AP-1 through L. barbarum polysaccharides. They claimed that isolated fractions of LBP affected the proliferation of $\mathrm{T}$ cells and enhanced production of Interleukin 2 and Interferon gamma (IFN $\gamma)$.

\section{PROTECTIVE PROPERTY OF GOJI ON RETINA CELLS}

A protective property of Goji extracts on retina cells has been proved in the early stage of the degeneration of the retina. It is proposed that absorbing the light zeaxanthin and luteolin present in Goji fruit displays an inhibitory effect on neuron apoptosis [Ni et al., 2013]. Yu et al. [2013] proved that bioactive compounds present in L. barbarum enhance the expression of zeaxanthin and luteolin genes in diabetic mice. It is postulated that inhibited expression of these genes can cause hyperglycemia. Thus, Goji berries display neuroprotective properties on a diabetic animal's retina. The neuroprotective effect of polysaccharide fractions on the retinal ganglion cells (RGC) in rats with high intraocular pressure (IOP) also contributes to the prevention of glaucoma [Chiu et al., 2010]. Tang et al. [2011] and $\mathrm{Hu}$ et al. [2012] also confirmed its protective influence on diabetic retinal injury. The protective property of $L$. barbarum extract on human retina neuron cells has also been demonstrated [Shen et al., 2012]. It is suggested that Goji extract containing taurine may inhibit the progress of diabetic retinopathy [Song et al., 2011]. 


\section{ANTIOXIDANT POTENTIAL}

Chemical analysis of Goji berry confirmed its high antioxidative activity. Based on the current analysis it was concluded that $L$. barbarum displays scavenging activity against free radicals (superoxide anion, hydroxyl radicals). Goji antioxidative activity is mainly attributed to carotenoid pigments, flavonoids, polysaccharide fraction and vitamin analog C-2-O-(beta-D-glucopyranosyl) ascorbic acid [Guo et al., 2008; Jiang, 2014; Li \& Zhou, 2007; Lin et al., 2009; Wang et al., 2010; Zhang et al., 2011 a,b]. One of the widely used markers of antioxidant potential is ORAC value (The Oxygen Radical Absorbance Capacity) [Gramza-Michałowska \& Korczak, 2013]. ORAC of fresh berries was found to be similar to cherry or red currant [USDA, 2010]. A comparison of ORAC values for the antioxidant activity of goji berries and other fruits is presented in Figure 1. ORAC assay results for fruits represent its antioxidant value, not proportionally however for the human body, because of the bioactive compounds absorption and metabolism. The effect of $L$. barbarum extract on the oxidative stress induced in liver of rats on high-fat diets was investigated. Changes in the liver tissue levels of malondialdehyde (MDA), glutathione, as well as activity of antioxidant enzymes (superoxide dismutase, catalase and glutathione peroxidase) and oxygen radical absorbance capacity were used as biomarkers of the protective effect of $L$. barbarum used as a dietary supplement. The decreased MDA level used as a marker of lipid peroxidation was observed in animals on high-fat diets supplemented with L. barbarum. Furthermore, increased concentrations of glutathione and antioxidant enzyme activities were evaluated [Cui et al., 2011]. The protective effect of L. barbarum extract on rats with alcohol-induced liver necrosis was investigated by Cheng \& Kong [2011]. Results showed that animals supplemented with Goji fruits extract exhibited decreased activity of alanine aminotransferase (ALT) and aspartate transaminase (AST), biomarkers of liver damage. Moreover, a decreased MDA concentration and a significant increase in antioxidant enzyme activity SOD, CAT, GPx and increased glutathione levels characterized rats supplemented with L. barbarum extract. Shan et al. [2011] analyzed the influence of Goji fruit polysaccharides on oxidative stress induced by physical activity. The L. barbarum supplemented-group was characterized by a decreased MDA content and higher levels of SOD and GPX, which confirmed protection against oxidative stress caused by physical activity. Li et al. [2007] performed an interesting experiment on mice supplemented with polysaccharide fraction and analyzed oxidative stress caused by ageing. They observed increased activity of endogenous antioxidant systems (SOD, CAT, GSH-Px), decreased levels of lipid peroxidation markers (MDA) and increased total antioxidative capacity in the organs of animals (lungs, liver, heart, and brain) supplemented with polysaccharide fraction of Goji berries [Li et al., 2007]. Then, Xiao et al. [2012] confirmed that this fraction exhibited liver-protective properties against the hepatotoxic oxidative stress inducer carbon tetrachloride. Reduced liver necrosis rates, increased activity of endogenous antioxidant system, and decreased lipid peroxidation expressed as MDA level were measured. Responses of humans supplemented with Goji juice exhibited similar patterns (increased
TABLE 3. Goji antioxidant capacity parameters evaluated with several methods.

\begin{tabular}{|c|c|c|c|c|}
\hline References & TEAC & FRAP & DPPH & $\mathrm{TPC}$ \\
\hline $\begin{array}{l}\text { Henning et al. } \\
\text { [2014] }\end{array}$ & $\begin{array}{c}2.7 \\
{[\mathrm{mmol}} \\
\mathrm{TE} / 100 \mathrm{~g}]\end{array}$ & $\begin{array}{c}0.9 \\
{[\mathrm{mmol}} \\
\mathrm{TE} / 100 \mathrm{~g}]\end{array}$ & $\begin{array}{c}1.4 \\
{[\mathrm{mmol}} \\
\mathrm{TE} / 100 \mathrm{~g}]\end{array}$ & - \\
\hline $\begin{array}{l}\text { Mocan et al. } \\
\text { [2014] }\end{array}$ & $\begin{array}{c}35.72 \\
{[\mu \mathrm{g} \mathrm{TE} / \mathrm{mg}]}\end{array}$ & - & $\begin{array}{c}29.30 \\
{[\mu \mathrm{g} \mathrm{QE} / \mathrm{mg}]}\end{array}$ & $\begin{array}{c}6159 \\
{[\mathrm{mg} \mathrm{GAE} / \mathrm{g}]}\end{array}$ \\
\hline $\begin{array}{l}\text { dos Reis et al. } \\
\text { [2014] }\end{array}$ & - & - & - & $\begin{array}{c}16.67 \\
{[\mathrm{mg} \mathrm{GAE} / \mathrm{g}]}\end{array}$ \\
\hline $\begin{array}{l}\text { Medina } \\
{[2011]}\end{array}$ & - & - & - & $\begin{array}{c}895 \\
{[\mathrm{mg}} \\
\mathrm{GAE} / 100 \mathrm{~g}]\end{array}$ \\
\hline $\begin{array}{l}\text { Donno et al. } \\
\text { [2015] }\end{array}$ & - & - & - & $\begin{array}{c}268.35 \\
{[\mathrm{mg}} \\
\mathrm{GAE} / 100 \mathrm{~g}]\end{array}$ \\
\hline
\end{tabular}

TEAC - Trolox Equivalent Antioxidant Capacity; FRAP - Ferric Reducing Antioxidant Potential; DPPH - 2,2'-diphenyl-1-picrylhydrazyl; TPC - Total Polyphenol Content; QE - Quercetin equivalents; TE - Trolox equivalents; GAE - Gallic Acid Equivalents

activity of antioxidant enzymes SOD and GSH-Px, and decreased lipid peroxidation) [Amagase et al., 2009a; Bucheli et al. 2011]. Wu et al. [2004] confirmed the scavenging activity against superoxide anions and inhibition of lipid peroxidation. Huang et al. [2001] also proved the antioxidative properties of $L$. barbarum. They showed that glycoconjugates present in Goji berries inhibit peroxidation of LDL-cholesterol fraction. Goji berries antioxidant capacity parameters evaluated with several methods were presented in Table 3.

\section{SAFETY ISSUES}

Wolfberries have attracted rapidly growing attention for their documented nutrient value, which has led to a profusion of consumer products. Goji products can be bought in health food stores in Europe and North America, and are advertised as natural mood boosters with anti-ageing properties. The reported health-promoting biological effects of L. barbarum indeed justify the term "superfruit". While Goji berries have many health benefits, there are some side effects that consumers need to be aware of (the presence of toxic substances, risk of allergies and interactions with other medications).

The controversially high content of atropine $(0.95 \%)$, a toxic alkaloid naturally present in Goji fruit, was tested in berries from India in 1989. However, published case reports do not describe people who have experienced atropine poisoning [Harsh, 1989]. Adams et al. [2006] carefully tested atropine levels by means of HPLC-PAD and TLC methods. They were not able to detect atropine. Using HPLC-MS, a small amount of atropine was found, with a maximum content of $19 \mathrm{ppb}$, well below a toxic level.

Allergic reactions to Goji berries rarely occur and only a few cases have been described. Monzón Ballarín et al. [2011] described the first two cases of patients who experienced allergic symptoms after Goji berry consumption. First woman developed anaphylaxis after eating Goji berries, accompanied by acute generalized urticaria on the hands, palms and lips, edema, dyspnea, and acute rhinitis; and second who reported generalized urticaria, severe pruritus and skin lesions (hives), 
angioedema, and dysphagia after Goji berry consumption. The skin prick tests were positive for Goji berry. Additional tests confirmed an allergy to Goji berries in both cases. Lipid transfer proteins (LTPs) seem to be involved in allergic sensitization to $L$. barbarum berries, and results have demonstrated a high degree of cross-reactivity between Goji berry and peach and tomato [Carnes et al., 2013; Larramendi et al., 2012].

Three published case reports have described patients who experienced interactions between Goji berry and warfarin, an anticoagulant drug. An elevated International Normalized Ratio (INR) was observed in patients after drinking Goji tea and juice, previously stabilized on anticoagulation therapy, also increased bleeding from rectum and nose was observed [Lam et al., 2001; Leung et al., 2008; Rivera et al., 2012]. Possible interactions between Goji and prescription medications are still unknown, thus the risks of wolfberries should be taken into consideration in individuals who take medications with a narrow therapeutic index.

\section{CONCLUSIONS}

Goji berry is well-known in traditional Chinese medicine and has been utilized as an important element of a health-promoting diet for hundreds of years. Recently, there has been rapidly growing attention surrounding wolfberries in the Western world. Health food stores provide a rich variety of Goji products, such as dried fruits, tea, beer, juice, sweets, musli and supplements [Potterat, 2010]. L. barbarum is a plant that could be cultivated in Europe. The main aim of this review was to gather and present state of the art data regarding the health-promoting properties of Goji fruits. Goji berry is a source of many bioactive compounds, characterized by high antioxidant potential. Goji fruits with a wide spectrum of biological effects have numerous implied health effects. Wolfberry may be an effective supplement in prophylaxis of diseases of affluence, such as diabetes, cardiovascular diseases and cancer. Goji is a safe food supplement, free from toxins; however, it can cause allergies; thus, the risks should be taken into consideration in individuals with food allergies, due to the high degree of cross-reactivity between wolfberry and peach and tomato. On the grounds of harmful herb-drug interactions that enhance drug performance, an anticoagulation therapy (warfarin) is a contra-indication to use Goji berry and any product containing wolfberry. The majority of published studies have used animal models in experiments. The results have been very optimistic and promising. However, additional research must be done with a greater number of experiments involving a larger number of animals, as well as experiments involving human subjects.

\section{ACKNOWLEDGEMENTS}

Financial support by the UE Project no. PO IG 01.01.02.00-061/09 "Bioactive Food" is greatly appreciated.

\section{REFERENCES}

1. Adams M., Wiedenmann M., Tittel G., Bauer R., HPLC-MS trace analysis of atropine in Lycium berries. Phytochem. Anal., 2006, 17, 279-283.
2. Ahmad S.R., Gokulakrishnan P., Giriprasad R., Yatoo M.A., Fruit based natural antioxidants in meat and meat products: a review. Crit. Rev. Food Sci. Nutr., 2015, 55, 1503-1513.

3. Amagase H., Farnsworth N.R., A review of botanical characteristics, phytochemistry, clinical relevance in efficacy and safety of $L y$ cium barbarum fruit (Goji). Food Res. Int., 2011, 44, 1702-1717.

4. Amagase H., Sun B., Borek C., Lycium barbarum (goji) juice improves in vivo antioxidant biomarkers in serum of healthy adults. Nutr. Res., 2009a, 29, 19-25.

5. Amagase H., Sun B., Nance D., Immunomodulatory effects of a standardized Lycium barbarum fruit juice in Chinese older healthy human subjects. J. Med. Food., 2009b, 12, 1159-1165.

6. Amani R., Gill T., Shiftworking, nutrition and obesity: implications for workforce health- a systematic review. Asia Pac. J. Clin. Nutr., 2013, 22, 505-515.

7. Astrup A., Kristensen M., Gregersen N.T., Belza A., Lorenzen J.K., Due A., Larsen T.M., Can bioactive foods affect obesity? Ann. N. Y. Acad. Sci., 2010, 1190, 25-41.

8. Batcagan-Abueg A.P.M., Lee J.J.M., Chan P., Rebello S.A., Amarra M.S.V., Salt intakes and salt reduction initiatives in Southeast Asia: a review. Asia Pac. J. Clin. Nutr., 2013, 22, 490-504.

9. Benzie I.F.F., Wachtel-Galor S., Herbal Medicine: Biomolecular and Clinical Aspects. 2011, 2nd ed. Boca Raton, FL: CRC Press.

10. Bucheli P., Vidal K., Shen L., Gu Z., Goji berry effects on macular characteristics and plasma antioxidant levels. Optom. Vis. Sci., 2011, 88, 257-262.

11. Carnés J., de Larramendi.CH., Ferrer A., Huertas A.J., López-Matas M.A., Pagán J.A., Peña M., Recently introduced foods as new allergenic sources: sensitisation to Goji berries (Lycium barbarum). Food Chem., 2013, 137, 130-135.

12. Castro I.A., Barroso L.P., Sinnecker P., Functional foods for coronary heart disease risk reduction: a meta-analysis using a multivariate approach. Am. J. Clin. Nutr., 2005, 82, 32-40.

13. Chen Z., Tan B.K.H., Chan S.H., Activation of T lymphocytes by polysaccharide-protein complex from Lycium barbarum L. Int. Immunopharmacol., 2008, 8, 1663-1671.

14. Cheng D., Kong H., The effect of Lycium barbarum polysaccharide on alcohol-induced oxidative stress in rats. Molecules, 2011, 16, 2542-2550.

15. Chiu K., Zhou Y., Yeung S.C., Lok C.K.M., Chan O.O.C., Chang R.C.C., Chiu J.F., Up-regulation of crystallins is involved in the neuroprotective effect of wolfberry on survival of retinal ganglion cells in rat ocular hypertension model. J. Cell Biochem., 2010, 110, 311-320.

16. Cho Y.H., Ahn S.C., Lee S.Y., Jeong D.W., Choi E.J., Kim Y.J., Lee J.G., Lee Y.H., Shin B.C., Effect of Korean red ginseng on insulin sensitivity in non-diabetic healthy overweight and obese adults. Asia Pac. J. Clin. Nutr., 2013, 22, 365-371.

17. Cui B., Liu S., Lin X., Wang J., Li S., Wang Q., Li S., Effects of Lycium barbarum aqueous and ethanol extracts on high-fatdiet induced oxidative stress in rat liver tissue. Molecules, 2011, 16, 9116-9128.

18. Dominion Seed House [online]., GOJI (Lycium barbarum) [access: 19-12-2013]. Retrieved from [http://www.dominion-seedhouse.com/upload/GOJI_AN.pdf].

19. Donno D., Beccaro G.L., Mellano M.G., Cerutti A.K., Bounous G., Goji berry fruit (Lycium spp.): antioxidant compound fingerprint and bioactivity evaluation. J. Funct. Food., 2015, doi:10.1016/j.jff.2014.05.020. 
20. dos Reis B.A., Kosińska-Cagnazzo A., Schmitt R., Andlauer W., Fermentation of plant material - Effect on sugar content and stability of bioactive compounds. Pol. J. Food Nutr. Sci., 2014, 64, 235-241.

21. Gan L., Zhang S.H., Liang Yang X., Bi Xu H., Immunomodulation and antitumor activity by a polysaccharide-protein complex from Lycium barbarum. Int. Immunopharmacol., 2004, 4, 563-569.

22. Gan L., Zhang S.H., Liu Q., Xu H.B., A polysaccharide-protein complex from Lycium barbarum upregulates cytokine expression in human peripheral blood mononuclear cells. Eur. J. Pharmacol., 2003, 471, 217-222.

23. Gramza-Michałowska A., Caffeine in tea Camellia sinensis content, absorption, benefits and risks of consumption. J. Nutr. Health Aging, 2014, 18, 143-149.

24. Gramza-Michałowska A., Korczak J., Oxygen radical absorbance capacity of selected food products. Acta Sci. Pol., Technol. Aliment., 2013, 12, 175-180.

25. Gramza-Michałowska A., Sidor A., Hęś M., Herb extract influence on the oxidative stability of selected lipids. J. Food Biochem., 2011, 35, 1723-1736.

26. Gross M.P., [online]., Exotic Antioxidant Superfruits. Volume 2: Goji ("Wolfberry") [access: 19-12-2013]. Retrieved from [http:// www.gojitrees.com/BerryDoctorGoji-GeneralEbook0-07.pdf].

27. Guiné R.P.F., Lima M.J.R., Barroca M.J., Functional components of Foods. 2010, in: Food, Diet and Health. Past, Present and Future Tendencies (ed. R.P.F. Guiné). Nova Science Publishers, New York, pp. 59-135.

28. Guo D.J., Cheng H.L., Chan S.W., Yu P.H.F., Antioxidative activities and the total phenolic contents of tonic Chinese medicinal herbs. Inflammopharmacology, 2008, 16, 201-207.

29. Guowen C., Longjun J., Qiang F., Anti-hyperglycemic activity of a polysaccharide fraction from Lycium barbarum. Afr. J. Biomed. Res., 2010, 13, 55-59.

30. Harsh M.L., Tropane alkaloids from Lycium barbarum Linn. in vivo and in vitro. Curr. Sci., 1989, 58, 817-818.

31. Henning S.M., Zhang Y., Rontoyanni V.G., Huang J., Lee R., Trang A., Nuernberger G., Heber D., Variability in the antioxidant activity of dietary supplements from pomegranate, milk thistle, green tea, grape seed, goji, and acai: effects of in vitro digestion. J. Agric. Food Chem., 2014, 62, 4313-4321.

32. Hęś M., Jeżewska M., Szymandera-Buszka K., Gramza-Michałowska A., Effect of antioxidant additives on nutritive value of dried meat. Zyw. Nauka Technol. Jakosc., 2011, 5, 94-106.

33. Hu C.K., Lee Y.J., Colitz C.M., Chang C.J., Lin C.T., The protective effects of Lycium barbarum and Chrysanthemum morifolum on diabetic retinopathies in rats. Vet. Ophthalmol., 2012, 15, 65-71.

34. Huang L.J., Tian G.Y., Wang Z.F., Dong J.B., Wu M.P., Studies on the glycoconjugates and glycans from Lycium barbarum $\mathrm{L}$ in inhibiting low density lipoprotein (LDL) peroxidation. Acta Pharm. Sin., 2001, 36, 108-111.

35. Inbaraj B.S., Lu H., Hung C.F., Wu W.B., Lin C.L., Chen B.H., Determination of carotenoids and their esters in fruits of $L y$ cium barbarum Linnaeus by HPLC-DAD-APCI-MS. J. Pharm. Biomed. Anal., 2008, 47, 812-818.

36. Jiang L., Preparation and antioxidant activity of Lycium barbarum oligosaccharides. Carbohydr. Polym., 2014, 99, 646-648.

37. Kmiecik D., Korczak J., Rudzińska M., Gramza-Michałowska A., Hęś M., Kobus-Cisowska J., Stabilization of phytosterols by natural and synthetic antioxidants in high temperature conditions. Food Chem., 2015, 173, 966-971.

38. Kris-Etherton P.M., Hecker K.D., Bonanome A., Coval S.M., Binkoski A.E., Hilpert K.F., Griel A.E., Etherton T.D., Bioactive compounds in foods: their role in the prevention of cardiovascular disease and cancer. Am. J. Med., 2002, 113, 71S-88S.

39. Lam A.Y., Elmer G.W., Mohutsky M.A., Possible interaction between warfarin and Lycium barbarum L. Ann. Pharmacother., 2001, 35, 1199-1201.

40. Larramendi C.H., García-Abujeta J.L., Vicario S., García-Endrino A., López-Matas M.A., García-Sedeño M.D., Carnés J., Goji berries (Lycium barbarum): risk of allergic reactions in individuals with food allergy. J. Investig. Allergol. Clin. Immunol., 2012, $22,345-350$.

41. Leung H., Hung A., Hui A.C.F., Chan T.Y.K., Warfarin overdose due to the possible effects of Lycium barbarum L. Food Chem. Toxicol., 2008, 46, 1860-1862.

42. Li X., Ma Y., Liu X., Effect of the Lycium barbarum polysaccharides on age-related oxidative stress in aged mice. J. Ethnopharmacol., 2007, 111, 504-511.

43. Li X., Zhou A., Evaluation of the antioxidant effects of polysaccharides extracted from Lycium barbarum. Med. Chem. Res., 2007, 15, 471-482.

44. Li X.M., Protective effect of Lycium barbarum polysaccharides on streptozotocin-induced oxidative stress in rats. Int. J. Biol. Macromol., 2007, 40, 461-465.

45. Lin C., Wang C., Chang S., Antioxidative activity of polysaccharide fractions isolated from Lycium barbarum Linnaeus. Int. J. Biol. Macromol., 2009, 45, 146-151.

46. Liu R.H., Dietary bioactive compounds and their health implications. J. Food Sci., 2013, 78, A18-25.

47. Liu X.L., Sun J.Y., Li H.Y., Zhang L., Qian B.C., Extraction and isolation of active component for inhibiting PC3 cell proliferation in vitro from the fruit of Lycium barbarum L. J. Chinese Materia Medica, 2000, 25, 481-483.

48. Llorent-Martínez E.J., Fernández-de Córdova M.L., Ortega-Barrales P., Ruiz-Medina A., Characterization and comparison of the chemical composition of exotic superfoods. Microchem. J., 2013, 110, 444-451.

49. Luo Q., Cai Y., Yan J., Sun M., Corke H., Hypoglycemic and hypolipidemic effects and antioxidant activity of fruit extracts from Lycium barbarum. Life Sci., 2004, 76, 137-149.

50. Mao F., Xiao B., Jiang Z., Zhao J., Huang X., Guo J., Anticancer effect of Lycium barbarum polysaccharides on colon cancer cells involves G0/G1 phase arrest. Med. Oncol., 2011, 28, 121-126.

51. Marczyński S., Piotrowski W., Clematis [online]. Encyclopaedia of vines [access: 07-12-2013]. Retrieved from [http://www. clematis.com.pl].

52. Marrazzo G., Barbagallo I., Galvano F., Malaguarnera M., Gazzolo D., Frigiola A., D’Orazio N., Li Volti G., Role of dietary and endogenous antioxidants in diabetes. Crit. Rev. Food Sci. Nutr., 2014, 54, 1599-1616.

53. Medina M.B., Determination of the total phenolics in juices and superfruits by a novel chemical method. J. Funct. Foods, 2011, 3, 79-87.

54. Meydani M., Hasan S.T., Dietary polyphenols and obesity. Nutrients, 2010, 2, 737-751.

55. Mikulic-Petkovsek M., Schmitzer V., Slatnar A., Stampar F., Veberic R., Composition of sugars, organic acids, and total pheno- 
lics in 25 wild or cultivated berry species. J. Food Sci., 2012, 77, C1064-1070.

56. Milner J.A., Molecular targets for bioactive food components. J. Nutr., 2004, 134, 2492S-2498.

57. Ming M., Guanhua L., Zhanhai Y., Guang C., Xuan Z., Effect of the Lycium barbarum polysaccharides administration on blood lipid metabolism and oxidative stress of mice fed high-fat diet in vivo. Food Chem., 2009, 113, 872-877.

58. Mocan A., Vlase L., Vodnar D.C., Bischin C., Hanganu D., Gheldiu A., Operan R., Silaghi-Dumitrescu R., Crisan G., Polyphenolic content, antioxidant and antimicrobial activities of Lycium barbarum L. and Lycium chinense Mill. leaves. Molecules, 2014, 19, 10056-10073.

59. Möller N.P., Scholz-Ahrens K.E., Roos N., Schrezenmeir J., Bioactive peptides and proteins from foods: indication for health effects. Eur. J. Nutr., 2008, 47, 171-182.

60. Monzón Ballarín S., López-Matas M.A., Sáenz Abad D., Pérez-Cinto N., Carnés J., Anaphylaxis associated with the ingestion of Goji berries (Lycium barbarum). J. Investig. Allergol. Clin. Immunol., 2011, 21, 567-570.

61. Morimoto A., Ohno Y., Tatsumi Y., Mizuno S., Watanabe S., Effects of healthy dietary pattern and other lifestyle factors on incidence of diabetes in a rural Japanese population. Asia Pac. J. Clin. Nutr., 2012, 21, 601-608.

62. Ni T., Wei G., Yin X., Liu X., Liu D., Neuroprotective effect of $L y$ cium barbarum on retina of Royal College of Surgeons (RCS) rats: a preliminary study. Folia Neuropathol., 2013, 2, 158-163.

63. Pai P., Habeeba P., Ullal S., Evaluation of hypolipidemic effects of Lycium barbarum (Goji Berry) in a murine model. J. Nat. Rem., 2013, 13, 4-8.

64. Peaceful Valley Farm Supply [online]. Goji (Wolf) Berries. Planting and growing guide [access: 21-12-2013]. Retrieved from [http://www.groworganic.com/media/pdfs/goji-l.pdf].

65. Peng X.M., Qi C.H., Tian G.Y., Zhang Y.X., Physico-chemical properties and bioactivities of a glycoconjugate LbGp5B from Lycium barbarum L. Chin. J. Chem., 2001, 19, 842-846.

66. Peng Y., Ma C., Li Y., Leung K.S.Y., Jiang Z.H., Zhao Z., Quantification of zeaxanthin dipalmitate and total carotenoids in $L y$ cium fruits (Fructus Lycii). Plant Foods Hum. Nutr., 2005, 60, 161-164.

67. Potterat O., Goji (Lycium barbarum and Lycium chinense): Phytochemistry, pharmacology and safety in the perspective of traditional uses and recent popularity. Planta Med., 2010, 76, 7-19.

68. Reguła J., Gramza-Michałowska A., New cereal food products with the addition of dried shiitake mushroom (Lentinula edodes) as a source of selected nutrients. Ital. J. Food Sci., 2010, 3, 292-297.

69. Reguła J., Gramza-Michałowska A., Nutritional value and glycemic index of cereal products with dried oyster mushroom (Pleurotus ostreatus) added. Żywność. Nauka, Technologia, Jakość, 2013, 5, $119-128$.

70. Rivera C.A., Ferro C.L., Bursua A.J., Gerber B.S., Probable interaction between Lycium barbarum (Goji) and warfarin. Pharmacotherapy, 2012, 32, e50-e53.

71. Saldanha G.L., Summary of comments received in response to the Federal Register notice defining bioactive food components. Federal Register, 2004, 69, 55821-55822.

72. Shan X., Zhou J, Ma T., Chai Q., Lycium barbarum polysaccharides reduce exercise-induced oxidative stress. Int. J. Mol. Sci., 2011, 12, 1081-1088.
73. Sharma R., Singh R.B., Bioactive foods and nutraceutical supplementation criteria in cardiovascular protection. Open Nutraceut. J., 2010, 3, 141-153.

74. Shashirakhaa M.N., Mallikarjunaa S.E., Rajarathnama S. Status of bioactive compounds in foods, with focus on fruits and vegetables. Crit. Rev. Food Sci. Nutr., 2015, 55, 1324-1339.

75. Shen Z., Wang J., Li G., Effect of extract of Lycium barbarum L. on adult human retinal nerve cells. Chin. J. Ophthalmol., 2012, $48,824-828$.

76. Sidor A., Gramza-Michałowska A., Advanced research on the antioxidant and health benefit of elderberry (Sambucus nigra) in food - a review. J. Funct. Foods, 2015, doi:10.1016/j. jff2014.07.012, in press.

77. Song M.K., Salam N.K., Roufogalis B.D., Huang T.H.W., Lycium barbarum (Goji Berry) extracts and its taurine component inhibit PPAR- $\gamma$-dependent gene transcription in human retinal pigment epithelial cells: Possible implications for diabetic retinopathy treatment. Biochem. Pharmacol., 2011, 82, 1209-1218.

78. Sopher L. Lauren. (n.d.)., Lycium barbarum L. climbers.lsa. umich.edu, (11), 1-5. Retrieved from [http://climbers.lsa.umich. edu/wpcontent/uploads/2013/07/LycibarbSOLAFINAL.pdf].

79. Srinath Reddy K., Katan M.B., Diet, nutrition and the prevention of hypertension and cardiovascular diseases. Public Health Nutr., 2004, 7, 167- 186.

80. Tang L., Zhang Y., Jiang Y., Willard L., Ortiz E., Wark L., Medeiros D., Lin D., Dietary wolfberry ameliorates retinal structure abnormalities in $\mathrm{db} / \mathrm{db}$ mice at the early stage of diabetes. Exp. Biol. Med., 2011, 236, 1051-1063.

81. Tang W.M., Chan E., Kwok C.Y., Lee Y.K., Wu J.H., Wan C.W., Chan S.W., A review of the anticancer and immunomodulatory effects of Lycium barbarum fruit. Inflammopharmacology, 2012, 20, 307-314.

82. USDA, U.S. Department of Agriculture, Agricultural Research Service. 2010. Oxygen Radical Absorbance Capacity (ORAC) of Selected Foods, Release 2. Nutrient Data Laboratory Home Page: http://www.ars.usda.gov/nutrientdata/orac

83. Wang C.C., Chang S.C., Inbaraj B.S., Chen B.H., Isolation of carotenoids, flavonoids and polysaccharides from Lycium barbarum L. and evaluation of antioxidant activity. Food Chem., 2010, 120, 184-192.

84. Wu S., Ng L., Lin C., Antioxidant activities of some common ingredients of traditional Chinese medicine, Angelica sinensis, Lycium barbarum and Poria cocos. Phytother. Res., 2004, 18, 1008-1012.

85. Xiao J., Liong E., Ching Y., Chang R., Lycium barbarum polysaccharides protect mice liver from carbon tetrachloride-induced oxidative stress and necroinflammation. J. Ethnopharmacol., 2012, 139, 462-470.

86. Yu H., Wark L., Ji H., Willard L., Jaing Y., Han J., Lin D., Dietary wolfberry upregulates carotenoid metabolic genes and enhances mitochondrial biogenesis in the retina of $\mathrm{db} / \mathrm{db}$ diabetic mice. Mol. Nutr. Food Res., 2013, 57, 1158-1169.

87. Zhang M., Chen H., Huang J., Li Z., Zhu C., Zhang S., Effect of Lycium barbarum polysaccharide on human hepatoma QGY7703 cells: inhibition of proliferation and induction of apoptosis. Life Sci., 2005, 76, 2115-2124.

88. Zhang Z., Liu X., Wu T., Liu J., Zhang X., Yang X., Wang Y., Selective suppression of cervical cancer Hela cells by $2-O-\beta-D-$ glucopyranosyl-L-ascorbic acid isolated from the fruit of Lycium barbarum L. Cell Biol. Toxicol., 2011a, 27, 107-121. 
89. Zhang Z., Liu X., Zhang X., Liu J., Hao Y., Comparative evaluation of the antioxidant effects of the natural vitamin $\mathrm{C}$ analog 2-O- $\beta$-D-glucopyranosyl-L-ascorbic acid isolated from Goji berry fruit. Arch. Pharm. Res., 2011b, 34, 801-810.

90. Zhao R., Li Q., Xiao B., Effect of Lycium barbarum polysaccharide on the improvement of insulin resistance in NIDDM rats. Yakugaku zasshi.J. Pharmaceut. Soc. Jap., 2005, 125, 981-988.

91. Zhong Y., Shahidi F., Naczk M., Phytochemicals and health benefits of goji berries. 2013, in: Dried Fruits: Phytochemicals and Health Effects, $1^{\text {st }}$ Edition (eds. C. Alasalvar, F. Shahidi). Wiley-Blackwell Publisher, Hoboken, New Jersey, pp. 133-144.

92. Zhu C.P., Zhang S.H., Lycium barbarum polysaccharide inhibits the proliferation of HeLa cells by inducing apoptosis. J. Sci. Food. Agric., 2013, 93, 149-156.

Submitted: 3 February 2015. Revised: 4 May and 31 May 2015. Accepted: 3 June 2015. Published on-line: 1 March 2016. 
